\title{
Explanation of the angle of sharpening of a plough cutting working body
}

\author{
Sergey V. Belousov ${ }^{1, *}$, Eugeny A. Saprykin ${ }^{1}$, and Ilya S. Karmazin ${ }^{1}$ \\ ${ }^{1}$ FSBEI HE Kuban State Agrarian University named after I.T.Trubilin, Krasnodar, Russian Federation
}

\begin{abstract}
The work is devoted to main tillage, namely the theoretical justification of the angle of sharpening of tillage working bodies. The article has a research character, which is expressed in the fact that the theoretical analysis of the method of determining the angle of sharpening of tillage working organs on the degree of gradual wear of working bodies. Also, the type of the proposed design is justified, its description and the flow of technological process are given. As a result of the work done, the theoretical dependence of the sharpening angle of the working bodies and the influence of the degree of wear on the traction resistance of the arable unit are obtained. The conclusions set out the main results achieved so far.
\end{abstract}

Designing of tillage equipment and units is a complex technological and production process. The most energy-full process is ploughing from the whole complex of field works. According to long-term data of leading scientists of the research Institute, up to $35-40 \%$ of energy and $22-30 \%$ of labor costs are required for ploughing. More and more metal-intensive and technological machines and units have appeared for tillage in recent years. So, recently many producers return to traditional technologies of crop cultivation and deep soil processing, both with a turn of a layer, or without it, occupies one of the important places.

For example, a deep tillage with mould board-free tillage units is applied in areas of high humidity, and in regions exposing wind erosion, tillage is made with working bodies. In other areas, it is more reasonable to produce soil treatment with the turnover of layer. So, according to scientists, the main part of roots of weeds and crop residues are in the layer up to $10 \mathrm{~cm}$, the so-called mulching layer, partially accumulates nutrients in the layer of $10-20 \mathrm{~cm}$, and such nutrients are at times more in layers of a deeper horizon. In connection with it, the mould board ploughing is the only environmentally friendly way to deliver these elements to upper soil layers, as in such processing the upper horizon moves to the bottom, and the lower one, on the contrary, up. Favorable conditions are created for the growth of cultivated plants [1].

Preparation of tillage units to work consists of a set of sequential actions, which

\footnotetext{
* Corresponding author: sergey belousov87@mail.ru
} 
include not only setting and adjustment of individual units and mechanisms of the arable unit, but also careful preparation of the tillage unit.

As it is known, the quality and traction resistance is affected by the preparation of all working bodies of the arable unit. Especially it is worth paying attention to sharpening elements that directly undercut the soil layer. Many factors depend on the quality of sharpening of working bodies [2].

Sharpening the blade can be represented as a flat wedge, on which forces of different in magnitude and direction appear on its surface, the profile of which is continuously changing during wear.

So, the wear of the blade can be shown in several stages. At the same time, the analysis of each of stages can be described in detail by the degree and quality of interaction of the knife with soil.

Consider the first step, Figure 1a,b, the shape and size of the profile are changed in this period of time, and the size of the cutting profile is changed only after setting the shape. According to the results of market analysis and advanced research, mainly 2 types of blades, Figure 1a,b, the profile of which (cutting edge, sharpening) is in the range of 0.1-0.2 mm are used in tillage units [3]. According to V. I. Vinogradov's researches, the process of cutting of merged soils by a blade of such profile is accompanied by the formation of the compacted kernel, namely soil crushing with braking of a plastic zone and its failure after the end of formation of profile of way $\delta$.

The blade on Figure $1 \mathrm{~b}$ in the depth of a profile consists of facet from an obverse side, because $\alpha_{0}=\geq 90^{\circ}-\varphi$ and sliding of soil particles under implementation of a blade with such a profile is absent. The present fact testifies that the compaction is formed and it leads to partial breaking of a working organ in the present zone, and it influences in complex of working elements of the plough on traction resistance of the whole tillage unit [4].

Modern tillage tools contain the so-called renewable layer, which contributes to the self-sharpening of working bodies. In the process of wear, such a blade which contains a hard alloy surfacing, takes the form of a profile, which is shown in Figure 2 with a blade thickness $t$, equal to the projection of the section $A B$ of the parabola on $\mathrm{Z}$ axis. The wear of the blade which are shown in Figure $1 \mathrm{a}, \mathrm{b}$, on soils with difficult conditions which were shown in Figure 3, the thickness of the blade $t_{\mathrm{z}}$ equal to the projection of the occipital part of the facet $A D$ on $Z$ axis is obtained. When working on overcompacted soils, the blade will take the form shown in Figure 4 in which the blade thickness can be taken as the sum $\mathrm{t}=\mathrm{t}_{3}+\mathrm{t}_{\pi}$ and the projections of parabolas $A B$ and $A C$ on $Z$ axis. In turn, there is no sliding of particles at the $B C$ site due to the condition [5].

$$
\begin{aligned}
& \alpha_{0}=\geq 90^{\circ}-\varphi \\
& \alpha_{0}=\geq 90^{\circ}-\varphi
\end{aligned}
$$

While the introduction of the wedge into the soil the compaction is formed at the site $\mathrm{CB}$ and the sliding of particles on the sections $B K$ and $C D$. The impact of the site $B K$ of the wedge (working body) promotes cracking and tearing of the layer or layer of soil. The $C D$ section implements compaction of the bottom of the furrow. This effect can be perceived as a negative factor that increases traction resistance.

Figure 6 shows the profile of the blade with ribs, this type of working bodies is often found in ploughs and cultivators of foreign firms [6]. This working body is a 
thin blade with ribs. The thickness of the blade of this form on a length of up to 50 $\mathrm{mm}$ is within up to $2 \mathrm{~mm}$. Ribs up to $4 \mathrm{~mm}$ thick with an interval of up to $35 \mathrm{~mm}$ provide the necessary strength when working in different conditions, but not clogged with stones [7]. The cross-section profile of the thin knife in Figure 5 is similar to the blade profile shown in Figure 4.

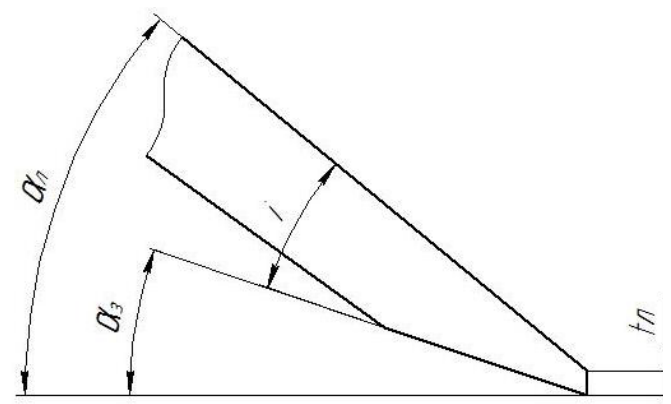

a

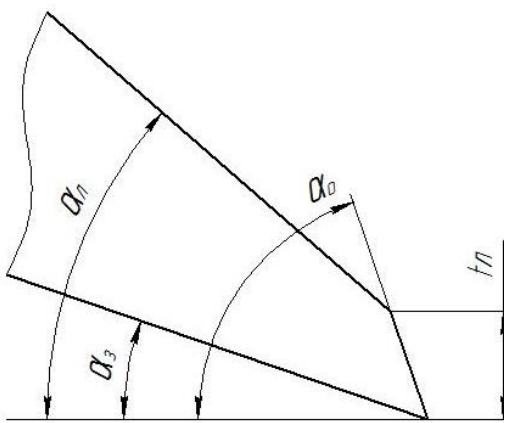

b

$\mathrm{a}$ - new blade with lower sharpening, $\mathrm{b}$ - new blade with upper sharpening.

Fig 1. Types of blades and their cutting edges

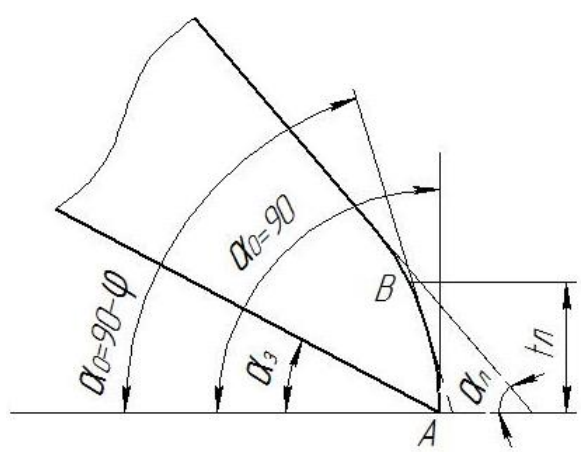

Fig. 2. Blade in the process of wear of first order.

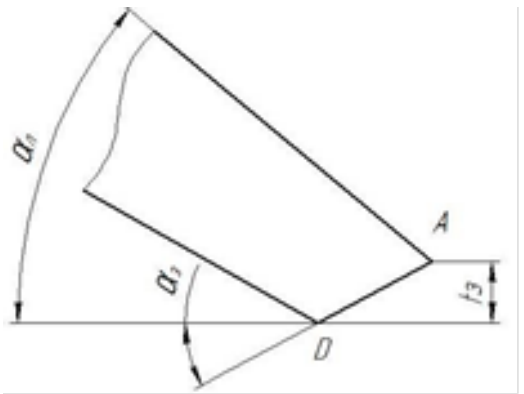

Fig. 3. Blade in the process of wear of second order.

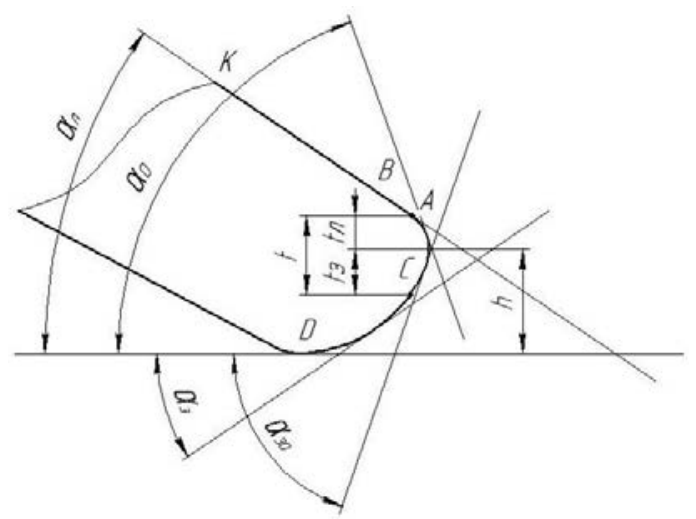

Fig. 4. Blade in the process of wear of third order. 


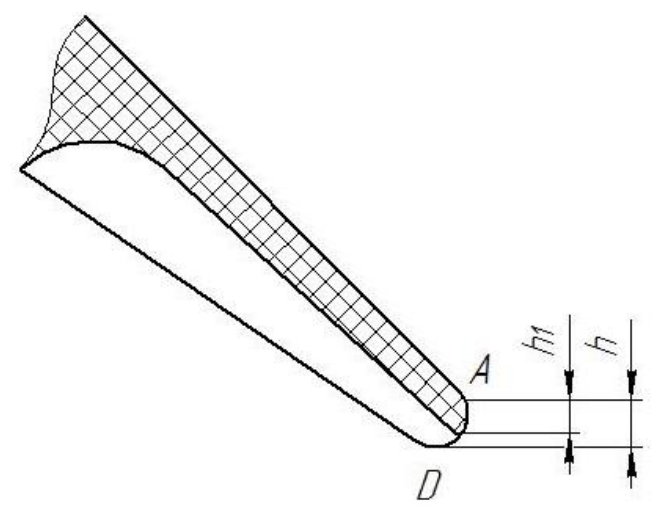

Fig. 5. Profile of the blade with ribs.

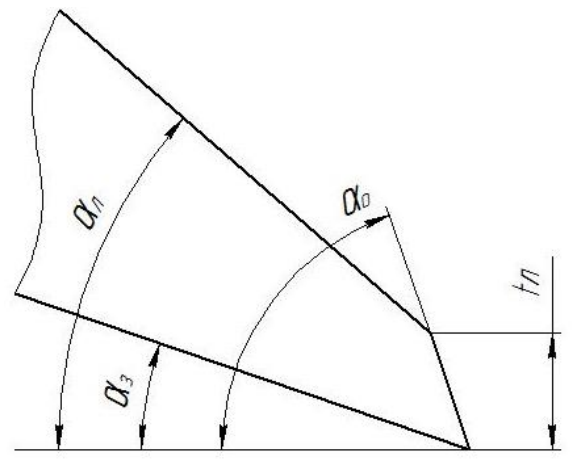

a

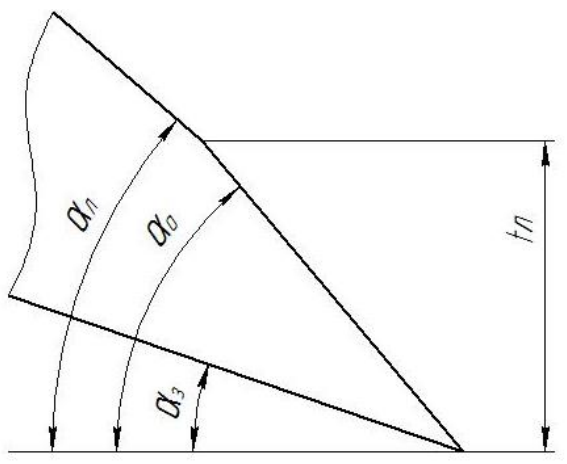

b

Fig. 6. Proposed profile of the blade.

As can be seen from Figure 6, the proposed profile of the working body of Figure $6 \mathrm{~b}$, its angle $\alpha_{o}$ has a smaller frontal angle of attack compared to the same attached working organs of Figure $6 \mathrm{a}$. From theoretical researches and field tests made, we find that the working body has a large mean time to failure and it is worn longer to the tear of the first order, and respectively to the second one [8].

As it was shown on theoretical researches, the leading scientists recommend to use not very sharpened edge of the blade, because in the process of operation the sharpening $\alpha_{o}$ has a smaller thickness in comparison with the main working body that do not have an additional angle of attack. We also proposed to introduce the additional angle of attack and as a result, increasing the thickness of the frontal profile of sharpening. It will increase the sharpening area of the working body, and as a result, these working bodies will not wear out longer, and the cutting process and interaction with soil will be more effective. This will reduce the traction resistance of the arable unit [9].

According to the results of the work done, a number of conclusions can be drawn: the angle of sharpening of the plane-cutting working body for layer-by-layer tillage with reservoir rotation is determined. This working body can be used as a part of the arable unit for the main mould board tillage with the turnover of the layer, and for mould board-free treatment [10]. The obtained theoretical dependences of the parameters and values can be used in further work on the study of parameters and dependencies of the interaction of tillage working bodies, both for the main and for surface tillage. 


\section{References}

1. Trubilin E.I. Results of experimental studies determining the degree of traction resistance of the plowshoe in the treatment of heavy soils / Trubilin E.I., Belousov S.V., Lepshina A.I. // The Political Network Electronic Scientific Journal of the Kuban State Agrarian University. -2014. -No. 103.-C. 673-686.

2. Rykov, V.B. Dynamics of moisture transfer in the soil, depending on the technology of its processing and cultivated crops / V.B. Rykov, S.I. Kambulov, I.A. Kambulov, E.B. Demina // In collection: Innovative development of the agro-industrial complex of Russia on the basis of intellectual machine technologies. Collection of scientific reports of the International Scientific and Technical conference. - 2014. - p. 205-208.

3. Kulintsev, V.V. The fundamentals of the new generation agriculture system in the Stavropol Territory: monograph / V.V. Kulintsev, E.I. Godunova, L.I. Zhelnakova. - Stavropol: AGRUS Stavropol GAU. - 2013. - 96 p.

4. Belousov S.V. Communication of science and technology in the field of development of machines for the basic tillage of the soil with the circulation of the bed / Belousov S.V. // The political network electronic scientific journal of the Kuban State Agrarian University. -2015. No. 109.-C. 468-486.

5. Pakhomov, V.I. Experience in the cultivation of winter wheat in conditions of insufficienthumidification / V.I. Pakhomov, V.B. Rykov, S.I. Kambulov, N.V. Shevchenko, E.L. Revyakin. - Moscow, 2015. - 160 p.

6. Parkhomenko G.G. Perfection of working organs for tillage / Parkhomenko GG, Bozhko I.V., Semenikhina Y.A., Pantyukhov I.V., Drozdov S.V., Gromakov A.V., Kambulov S.I., Belousov S.V. // State and prospects of the development of agricultural machinery. Collection of articles of the 9th international scientific and practical conference within the framework of the 19th international agroindustrial exhibition "Interagro-mash-2016". -2016. -FROM. 27-30.

7. Gyachev, L.V. The theory of a dumping - dumping surface / L.V. Gyachev. Zernograd, 1961. - 317

8. Belousov S.V. Patent search for structures that provide soil treatment with the turnover of the reservoir. Search method. The proposed technical solution / Belousov S.V. // The political network electronic scientific journal of the Kuban State Agrarian University. -2015. No. 109.-C. 416-450.

9. Amaeva, A.G. Influence of soil moisture conditions on the bioresource potential of highly productive maize hybrids of various ripeness in the Chechen steppe zone Republic / A.G. Amaeva, M.Kh. Kavarnukaeva, N.L. Adaev // Proceedings of the Gorsky State Agrarian University. - T.50. - №1. - pp. 31-37.

10. Belousov S.V. Role and prospects for the development of small-scale mechanization in the context of co-temporary engineering / Belousov S.V. I Scientific support of the agro-industrial complex. A collection of articles on the materials of the 72nd Scientific and Practical Conference of pre-applicants on the results of research work for 2016 - 2017.-C. 277-278. 